\title{
Immunodetection of SV40 large T antigen in human central nervous system tumours
}

\author{
J Sabatier, E Uro-Coste, A Benouaich, S Boetto, M Gigaud, M Tremoulet, M-B Delisle, F Galateau- \\ Sallé, P Brousset
}

J Clin Pathol 2005;58:429-431. doi: 10.1136/jap.2004.020131

Background/Aims: DNA sequences from Simian virus 40 (SV40) have been previously isolated from various human tumours of the central nervous system (CNS). This study aimed to investigate a series of tumours of the CNS for the expression of the SV4O large T antigen (Tag), which is an oncogenic protein of the virus.

Methods: A French series of 82 CNS tumours was investigated for Tag expression using a monoclonal antibody and immunohistochemistry. A Tag positive hepatocellular carcinoma cell line from transgenic mice and a kidney biopsy from a patient infected by SV4O were used as positive controls.

Results: None of the tumours (20 ependymomas, 20 glioblastomas, 12 oligodendrogliomas, three plexus choroid adenomas, two plexus choroid carcinomas, 15 meningiomas, and 10 medulloblastomas) contained SV40 Tag positive cells.

Conclusions: The lack of SV40 Tag in 82 CNS tumours of various types is at variance with previous studies from different countries, and suggests that the virus may not be an important factor in CNS tumorigenesis, at least in French cases.

$\mathrm{T}$ he JC and BK viruses are now considered to be ubiquitous human pathogens. These viruses are reactivated under impaired physiological conditions such as immunosuppression. ${ }^{1-3} \mathrm{JC}$ virus DNA sequences have been isolated from several human central nervous system (CNS) tumours, including medulloblastoma, ependymoma, and a broad range of tumours with a glial origin. ${ }^{12}$ Simian virus 40 (SV40), a monkey virus that can induce cancer in mice, has now been isolated from a variety of human cancers such as mesothelioma, ependymoma, and non-Hodgkin lymphoma. ${ }^{13-5}$ The transmission of SV40 to humans remains unclear, although some patients might have been infected through contaminated polio vaccines. These vaccines were prepared in primary cultures of Rhesus monkey kidney cells and some were infected with SV40. ${ }^{12}$ Accumulating data indicate that SV40 is implicated in different human tumours, but most studies have relied on polymerase chain reaction (PCR) detection of viral DNA sequences.

\section{"The transmission of Simian virus 40 to humans remains unclear, although some patients might have been infected through contaminated polio vaccines"}

There are still controversies as to whether SV40 is directly linked to cancer development. ${ }^{136} \mathrm{~A}$ few studies have found that the SV40 genome was present in mesothelioma, and that its main oncogene-large T antigen (Tag)—was expressed at the protein level and was complexed with p53 and the retinoblastoma protein in some tumours. ${ }^{78}$ Although immunodetection of SV40 Tag could be used as a diagnostic marker of human mesothelioma, it is not used in routine pathology.

We investigated a French series of tumours of the CNS by means of immunohistochemistry, using a monoclonal antibody directed against Tag. This antibody worked well on routinely processed, formalin fixed and paraffin wax embedded sections after antigen retrieval.

\section{MATERIAL AND METHODS \\ Tissues samples}

Various types of CNS tumours were retrieved from our files at the Purpan Hospital in Toulouse, France between 1990 and 2003. Most cases were processed routinely; that is, fixed in Bouin's liquid and/or in 10\% buffered formalin. There were 20 ependymomas, 20 glioblastomas, 12 oligodendrogliomas, three plexus choroid adenomas, two plexus choroid carcinomas, 15 meningiomas, and 10 medulloblastomas. The age of the patients was between 3 and 78 years.

\section{Immunohistochemistry}

Antibody

An anti-Tag monoclonal antibody (Ab-2; clone Pab416) from Oncogene Research Products (San Diego, California, USA) was used. It worked well on paraffin wax embedded sections of tissues fixed in 10\% buffered formalin or in Bouin's liquid. Staining of the positive controls was achieved after standard antigen retrieval and/or after amplification of the signal by catalysed system amplification (CSA; Dako, Carpintera, California, USA). However, we preferred standard antigen retrieval because CSA gave rise to high background staining.

\section{Technique}

Immunostaining on paraffin wax embedded sections was performed using a method described previously, ${ }^{9}$ with some modifications. Briefly, paraffin wax embedded sections were mounted on glass slides coated with silane (Sigma Chemical Co, Saint Quentin, France). Sections were dewaxed, placed in $10 \mathrm{mmol} /$ litre Na-citrate buffer $(\mathrm{pH} \mathrm{6.0)}$, and heated in a microwave oven (Whirlpool model; Philips, Eindhoven, the Netherlands) at $900 \mathrm{~W}$ for cycles of 20 and 10 minutes. The slides were removed from the oven and allowed to cool for 30 minutes at room temperature. A 1/100 dilution of the Ab-2 antibody was added and the slides incubated at room temperature for 30 minutes. After washing in water, endogenous peroxidase was blocked with $1 \%$ hydrogen peroxide in methanol for 30 minutes. Slides were then rinsed in phosphate buffered saline before staining with a streptavidin-biotin three stage technique, with the Dako Strept ABC

Abbreviations: CNS, central nervous system; CSA, catalysed system amplification; PCR, polymerase chain reaction; SV40, Simian virus 40; $\mathrm{Tag}$, Simian virus 40 large $T$ antigen 
complex/horseradish peroxidase Duet kit (Dako; code K492). For the CSA technique, we used the Dako kit according to the supplier's recommendations. The Dako CSA system is an extremely sensitive immunohistochemical staining procedure incorporating a signal amplification method based on the peroxidase catalysed deposition of a biotinylated compound, followed by a secondary reaction with streptavidin peroxidase (Dako).

\section{Controls}

Positive controls consisted of a hepatocellular carcinoma cell line from Tag transgenic mice. ${ }^{10}$ The cells were fixed in Bouin's liquid and formalin before being embedded in paraffin wax blocks. Another control was provided by a kidney biopsy from a transplant recipient who had an active SV40 infection (confirmed by PCR in urine) and may represent an in vivo model of SV40 infection as reported by Li et al. ${ }^{11}$ However, in the recent work by Low et al, ${ }^{12}$ it has been shown that the Ab-2 antibody can detect BK virus. Nevertheless, the kidney control included in our study shows that Ab-2 works well and reproducibly in routinely processed tissues.

Negative (DNA negative) controls comprised five tissue sections from Tag PCR negative lung tumours and nonneoplastic tissues. ${ }^{13}$

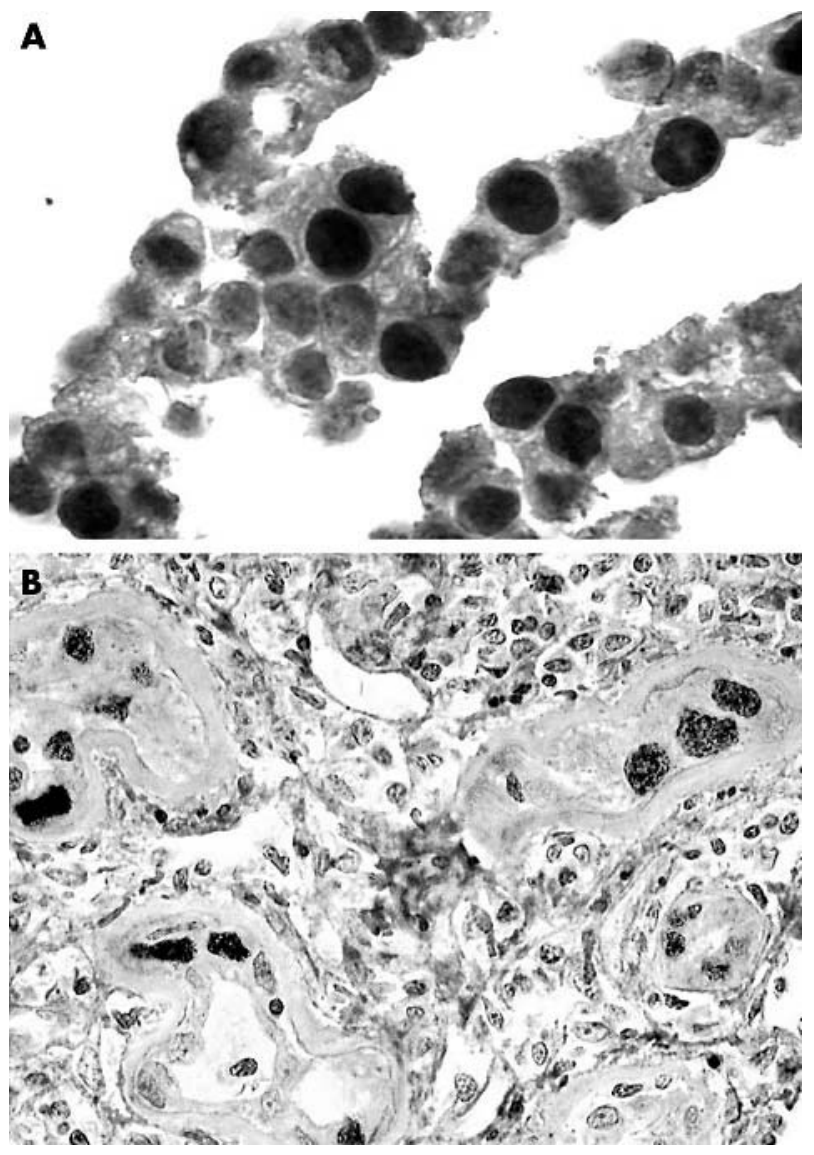

Figure 1 (A) Positive nuclear immunostaining of the formalin fixed and paraffin wax embedded hepatocellular carcinoma cell line with a monoclonal anti-Simian virus 40 (SV40) large T antigen (Tag) antibody (Ab-2). Horseradish peroxidase; original magnification, $\times 1000$. (B) Positive immunostaining for Tag (Ab-2 antibody) seen in a paraffin wax embedded kidney biopsy section from a transplant patient with active SV40 infection. Nuclear staining of dystrophic tubular cells. Horseradish peroxidase; original magnification, $\times 1000$.

\section{RESULTS AND DISCUSSION}

Tag was detectable without amplification in hepatocarcinoma cells fixed either in 10\% buffered formalin or in Bouin's liquid and in tubular cells from the kidney biopsy (fig 1A, B). The signal was strong, mainly nuclear, and showed subtle variations in intensity from one cell to another, probably as a result of variations in fixation intensity. Negative controlsnon-neoplastic tissues and tissues for which PCR detection of SV40 Tag DNA was negative ${ }^{13}$ - were negative when stained with the anti-Tag antibody. This was particularly clear for tissues fixed in Bouin's liquid, whereas some formalin fixed samples (PCR negative) showed weak non-specific nuclear staining of neoplastic and non-neoplastic cells.

In our series of 82 CNS tumours, no cases were positive for Tag by immunohistochemistry. In particular, plexus choroid tumours and ependymomas were negative, although other studies have shown a constant or frequent association of these tumours with SV40. ${ }^{14}$

"The results obtained in the kidney biopsy strongly suggest that our technique is relatively sensitive because this control represents an in vivo model of Simian virus 40 infection"

JC virus and BK virus are thought to be ubiquitous human pathogens, ${ }^{12}$ but the epidemiology of SV40 is less clear. The transmission of SV40 to humans is still unknown, although some patients might have been infected by contaminated polio vaccines. ${ }^{1-3}$ SV40 is a monkey virus that can induce cancer in mice (but not in monkeys), and has been detected in different types of cancer in humans. In addition to mesothelioma and CNS tumours, SV40 DNA sequences have been detected in non-Hodgkin lymphomas. ${ }^{1-5} 7814$ Despite accumulating data suggesting that SV40 is implicated in human cancers, it is worth mentioning that most of the studies published to date have been based on the PCR detection of viral DNA. Therefore, a direct role for the virus in human oncogenesis remains to be confirmed. A few studies found that the SV40 genome was present in mesothelioma, and that its main oncogene (Tag) was expressed at the protein level, complexed with p53 and the retinoblastoma protein in some tumours. ${ }^{78}$ However, immunodetection of SV40 Tag is not commonly recognised as a diagnostic marker that can distinguish between mesothelioma and adenocarcinoma or between mesothelioma and reactive mesothelial hyperplasia. It is difficult to explain the lack of reproducibility of immunohistochemistry because there are specific anti-Tag monoclonal antibodies that work well on paraffin wax embedded sections. All of our cases were tested in parallel with a highly sensitive immunohistochemical signal amplification method (the CSA method), but a signal was obtained with the positive controls only. However, it could be argued that the positive cell line used in our study contains large amounts of Tag protein, and that the method used was not sensitive enough to detect smaller amounts. Nevertheless, if SV40 does play a role in the development of CNS tumours, Tag ought to be expressed at sufficiently high levels to elicit its oncogenic effects. Of note, other viral proteins with a nuclear localisation (for example, EpsteinBarr virus EBNA2, human herpesvirus 8 LANAl, human papillomavirus E6, etc), some of which have oncogenic properties, are constantly detectable in target cells with specific antibodies. ${ }^{915}{ }^{16}$ However, the results obtained in the kidney biopsy strongly suggest that our technique is relatively sensitive because this control represents an in vivo model of SV40 infection.

Another explanation for the negative results would be a bias in the selection of patients. However, among the 82 


\section{Take home messages}

- Although DNA sequences from Simian virus 40 (SV40) have been previously isolated from various human tumours of the central nervous system (CNS), we found no evidence of the SV40 large T antigen in a French series of 82 CNS tumours using immunohistochemistry

- A Tag positive hepatocellular carcinoma cell line from transgenic mice and a kidney biopsy from a patient infected by SV40 were used as positive controls

- This suggests that the virus may not be an important factor in CNS tumorigenesis, at least in French cases

patients selected for our study, 43 were at risk for poliovirus vaccine driven SV40 contamination (possible vaccination between 1955 and 1963). A recent meta-analysis of data from 589 primary brain cancer samples and 414 control samples conclusively established that SV40 is significantly associated with those malignancies. ${ }^{17}$ Although very complete, that paper lacked important data, recently published ${ }^{6}{ }^{18}$ or in press, ${ }^{19}$ showing negative results in particular in lymphomas. In a recent study, ${ }^{19}$ using the same immunohistochemical approach, we were unable to detect positivity in 482 cases of lymphoma from France and Canada. Our results are clearly at variance with those recently presented at the meeting of the American Association for Cancer Research by Samaniego and colleagues $^{20}$ and Vilchez et al. ${ }^{2122}$ Samaniego et al, ${ }^{20}$ found an unusual pattern of staining with the anti-Tag (Pab419) antibody. Although nuclear staining was seen in their control cell line (as in our study), they found cytoplasmic staining in the lymphoma cells but consider it to be valid. ${ }^{20}$ In the two abstracts by Vilchez and colleagues ${ }^{21} 22$ the authors found a correlation between immunohistochemistry and PCR for detecting SV40 in lymphomas, but the details of the techniques used and the staining pattern with anti-Tag antibody are not given. Our study was based on immunohistochemistry with a single antibody, whereas other investigators have shown the expression of Tag in this group of tumours with different approaches (indirect immunofluorescence, PCR, immunohistochemistry, Southern blotting, and western blotting). ${ }^{14} 2324$ However, because we repeatedly detected Tag in two distinct controls processed by the same immunohistochemical method used for the tumour cases, we consider our results to be reliable.

Therefore, our negative results suggest a possible epidemiological variation of SV40 infection in human brain tumours in different countries.

\section{ACKNOWLEDGEMENTS}

This study was funded by La Ligue Contre le Cancer, Comités de la Haute-Garonne et du Gers.

\section{Authors' affiliations}

J Sabatier, S Boetto, M Gigaud, M Tremoulet, Department of Neurosurgery, Purpan Hospital, Place Baylac, 31059 Toulouse Cedex, France

A Benouaich, Department of Neurology, Purpan Hospital E Uro-Coste, M-B Delisle, Department of Pathology, Rangueil Hospital, 31059 Toulouse, Cedex 9, France
F Galateau-Sallé, Department of Pathology, CHU Caen, 14000 Caen, France

P Brousset, Department of Pathology, Purpan Hospital and INSERM

U563 (CPTP), CHU Purpan, Toulouse, France

Correspondence to: Dr P Brousset, Department of Pathology, Purpan Hospital, Place Baylac, 31059 Toulouse Cedex, France; brousset.p@ chu-toulouse.fr

Accepted for publication 14 September 2004

\section{REFERENCES}

1 Carbone M Pass HI, Miele L, et al. New developments about the association of SV40 with human mesothelioma. Oncogene 2003;22:5173-80.

2 Vilchez RA, Butel JS. SV40 in human brain cancers and non-Hodgkin's lymphoma. Oncogene 2003;22:5164-72.

3 Klein G, Powers A, Croce C. Association of SV40 with human tumors. Oncogene 2002;21:1141-9.

4 Bergsagel DJ, Finegold MJ, Butel JS, et al. DNA sequences similar to those of simian virus 40 in ependymomas and choroid plexus tumors of childhood. N Engl J Med 1992;326:988-93.

5 Martini F, laccheri L, Lazzarin L, et al. SV40 early region and large T antigen in human brain tumors, peripheral blood cells, and sperm fluids from healthy individuals. Cancer Res 1996;56:4820-5.

6 Vilchez RA, Madden CR, Kozinetz CA, et al. Association between simian virus 40 and non-Hodgkin lymphoma. Lancet 2002;359:817-23.

7 MacKenzie J, Wilson KS, Perry J, et al. Association between simian virus 40 DNA and lymphoma in the United Kingdom. J Natl Cancer Inst 2003;95:1001-3.

8 Carbone M, Rizzo P, Grimley PM, et al. Simian virus-40 large-T antigen binds p53 in human mesotheliomas. Nat Med 1997;3:908-12.

9 De Luca A, Baldi A, Esposito V, et al. The retinoblastoma gene family pRb/ $\mathrm{p} 105, \mathrm{p} 107, \mathrm{pRb} 2 / \mathrm{p} 130$ and simian virus-40 large T-antigen in human mesotheliomas. Nat Med 1997;3:913-16.

10 Brousset P, Cesarman E, Meggetto F, et al. Colocalization of the viral interleukin- 6 with latent nuclear antigen- 1 of human herpesvirus- 8 in endothelial spindle cells of Kaposi's sarcoma and lymphoid cells of multicentric Castleman's disease. Hum Pathol 2001;32:95-100.

11 Weber-Benarous A, Decaux JF, Bennoun M, et al. Retroviral infection of primary hepatocytes from normal mice and mice transgenic for SV40 large T antigen. Exp Cell Res 1993;205:91-100.

12 Li RM, Mannon RB, Keliner D, et al. BK virus and SV40 co-infection in polyomavirus nephropathy. Transplantation 2002;74:1497-504.

13 Low J, Humes HD, Szczypka M, et al. BKV and SV40 infection of human kidney tubular epithelial cells in vitro. Virology 2004;323:182-8.

14 Galateau-Salle F, Bidet P, Iwatsubo Y, et al. SV40-like DNA sequences in pleural mesothelioma, bronchopulmonary carcinoma, and non-malignant pulmonary diseases. J Pathol 1998;184:252-7.

15 Johannessen I, Perera SM, Gallagher A, et al. Expansion in scid mice of Epstein-Barr virus-associated post-transplantation lymphoproliferative disease biopsy material. J Gen Virol 2002;83:173-8.

16 Wiest T, Schwarz E, Enders C, et al. Involvement of intact HPV16 E6/E7 gene expression in head and neck cancers with unaltered p53 status and perturbed pRb cell cycle control. Oncogene 2002;21:1510-17.

17 Vilchez RA, Kozinetz CA, Arrington AS, et al. SV40 in human cancers. Am J Med 2003; 1 14:675-84.

18 Capello D, Rossi D, Gaudino G, et al. Simian virus 40 infection in lymphoproliferative disorders. Lancet 2003;361:88-9.

19 Brousset P, De Araujo V, Gascoyne RD. Immunohistochemical investigation of SV40 large T antigen in Hodgkin and non Hodgkin's lymphoma. Int $J$ Cancer 2004; 112:533-5.

20 Samaniego F, Wang S, Young D, et al. Large T antigen DNA and protein of Simian virus 40 in non-Hodgkin's lymphoma. Proc Am Assoc Cancer Res 2004;45:Abstract, 4762.

21 Vilchez R, Eldin K, Jaffe I, et al. Polyomavirus simian virus 40 positive lymphomas in children. Proc Am Assoc Cancer Res 2004;45:Abstract LB-172.

22 Vilchez R, Lopez-Terrada D, Finch CJ, et al. Expression of simian virus 40 large tumor antigen in non-Hodgkin's lymphomas among HIV-infected patients. Proc Am Assoc Cancer Res 2004;45:Abstract 4438.

23 Malkin D, Chilton-MacNeil S, Meister LA, et al. Tissue specific expression of SV40 in tumors associated with Li-Fraumeni syndrome. Oncogene $2001 ; 20: 4441-9$

24 Zhen $\mathrm{HN}$, Zhang $\mathrm{X}, \mathrm{Bu} X Y$, et al. Expression of the simian virus 40 large tumour antigen (Tag) and formation of Tag-p53 and Tag-pRb complexes in human brain tumors. Cancer 1999;86:2124-32. 